\title{
Fen Bilgisi Öğretmen Adaylarının Denklem Anlayışları ve Kimya Denklemlerini
}

\section{Anlama Düzeyleri \\ Sevgül ÇALIŞ*}

Öz: Bu çalışmada fen bilgisi öğretmen adaylarının genel denklem anlayışı ve kimya derslerinde öğrendiği veya bazı kimya konularının anlaşılmasında sıklıkla kullanılan denklemlerin, onların zihninde nasıl bir anlam ifade ettiği saptanmıştır. Bu amaçla yapılan çalışmada öğretmen adaylarına uzman görüşü alınarak hazırlanan altı adet açık uçlu soru yöneltilmiştir. Çalışmada araştırma sorularına yanıt aramak için, nitel araştırma yöntemlerinden biri olan betimsel analiz metodu kullanılmıştır. Çalışma 2017-2018 eğitim-öğretim yılı güz döneminde Uludağ Üniversitesi Eğitim Fakültesinde öğrenim gören toplam 50 birinci sınıf Fen Bilgisi öğretmeni adayı ile gerçekleştirilmiştir. Elde edilen veriler değerlendirildiğinde öğretmen adaylarının büyük bölümünün, denklem kavramını değişkenler arasındaki ilişkinin matematiksel ifadesi olarak tanımlayamadığı görülmüştür. Ayrıca kimya derslerinde kullanılan denklemlerde yer alan değişkenlerin birbiri ile olan ilişkisini açıklama ve denklemleri matematiksel olarak ifade etme konusunda da, yetersizlikleri olduğu saptanmıştır. Öğrencilerin denklemlerle günlük yaşamı ilişkilendirme konusunda da çok başarılı olmadıkları görülmüştür.

Anahtar Kelimeler: Denklem, kimya öğretimi, betimsel analiz, fen bilgisi öğretmen aday1

\section{Pre-service science teachers' understanding and level of comprehension of chemistry equations}

\begin{abstract}
In this study, it is aimed to give a deep insight into the teacher candidates' understanding of the general concept of "equation" and what those equations that science teacher candidates learn in chemistry classes or face with when they try to have a better
\end{abstract} Öğretmenliği AB.D., BURSA scalis@uludag.edu.tr ORCID NO:0000-0002-5195-3210

\begin{tabular}{lll}
\hline Gönderim: 17.05.2018 Kabul:19.07.2018 & Yayın:10.09.2018
\end{tabular}


understanding of a difficult topic mean to them. Six open-ended questions directed at the teacher candidates in this study were applied under four different headings. The descriptive analysis method, which is one of the qualitative research methods, was used to search for answers to research questions in the study. The study was conducted with a total of 50 firstyear science teachers who were educated at the Uludag University Faculty of Education during the fall semester of the 2017-2018 academic year. When the obtained data are evaluated, it has been determined that most of the teacher candidates have insufficiency about making scientific definitions of the given equations, explaining the relationship between the quantities in the chemical equations and expressing the equations mathematically. One of the most striking results is that although students tried to give examples from everyday life appropriate to the equations, none of the students was successful in finding an analogy.

Keywords: Chemistry teaching, equations, descriptive analysis, pre -service science teachers

\section{Giriş}

Matematik bilmek ve matematik bilgisini kullanabilmek fen derslerinde başarılı olabilmenin temel koşullarından en önemlisidir (Ergül, 2018, Özdemir, 2006). Çünkü denklemlerdeki matematiksel ilişkiyi görebilen öğrenciler, denklemlerdeki büyüklükler arasındaki ilişkiyi daha iyi yorumlayabilir. Öğrencilerin temel fen derslerinde matematik kullanma bilgi ve becerileri ders başarılarını etkileyen temel faktörlerdendir. Konuyla ilgili pek çok araştırma; psikomotor beceriler, bilimsel süreç becerileri ve alan bilgisi gibi faktörlerin ilgili bilim disiplinindeki başarıyı etkilemesinin yanı sıra, gerekli matematiksel beceriyi öncelikli bir özellik olarak tanımlamıştır (Scott, 2012; Deringöl ve Gülten, 2016; Yaman ve Gülten, 2015).

Matematik, öncelikle fiziğin hem öğretiminde hem de uygulanmasında derinlemesine etkilidir. Bununla birlikte kimya, biyoloji, jeoloji ve meteoroloji gibi diğer bilimler sıklıkla 
matematik kullanırlar (Redish ve Kuo, 2015). Galileo’nun ‘evren matematiksel dil kullanılarak yazıldı’ (Yıldırım, 2005) ifadesi fen bilimleri için matematiğin önemine vurgu yapmaktadır. Matematiğin fizikte kullanımı ve önemine ait pek çok çalışma olmasına rağmen (Tuminaro, 2002), matematik ve kimya arasındaki ilişkiyi irdeleyen çalışmalara rastlanmamaktadır.

Öğrencilerin, her seviyede matematiksel bilgiyi kullanmada sorun yaşadıklarını ortaya koyan çalışmalar yapılmıştır. Örneğin, Sherin (2001) üniversite öğrencilerinin fizik problemlerini çözmede matematiksel sembol kullanımında yaşanılan sorunlara dikkat çekmiştir. Fen ve mühendislik öğrencileri ile yapılan bir çalışmada, fen bilimlerinde birim ve sembolleri kullanmada öğrencilerin büyük problem yaşadıkları ortaya konmuştur (Gök, 2016). Yine üniversite öğrencileri düzeyinde yapılan bir başka çalışmada kimyadaki; kinetik, kimyasal denge, entropi ve serbest enerji, asit baz kimyası ve elektrokimya gibi konuların işlenmesinde matematiksel ifadenin öneminden bahsedilmiş ve yaşanan sıkıntılar dile getirilmiştir (Leopold ve Edgar, 2008). İlköğretim Fen ve teknoloji derslerinde öğrencilerin fen konularını öğrenmede matematiksel bilgi eksikliğinin yarattığı sıkıntıları ifade eden bir çalışma, Bütüner ve Uzun (2011) tarafında yapılmıştır. Matematik bilgiyi kullanmada yaşanılan sıkıntıyı dile getiren başka çalışmalar da mevcuttur (Örneğin, Sujak ve Daniel, 2017; Redish ve Kuo, 2015; Tutak, Gül ve Emür, 2010; Scott, 2012; Ogilvie ve Monagan, 2007; Milne, 1997; Yenilmez, 2007). Öğrencilerin matematik bilgisini kullanmada sorun yaşamalarının en önemli nedenlerinden biri matematik ve fen derslerinin iyi entegre edilememiş olmasıdır ve bu problem matematik ve fen dersleri arasında bir uçurum oluşturmaktadır (Temel, Dündar ve Şenol, 2015).

Kimya derslerinde matematik kullanma becerisi gerektiren mol ve eşdeğerlik kavramları, kimyasal tepkimelerde hesaplamalar, stokiyometri, bileşik formüllerinin belirlenmesi, gaz yasaları, derişim birimleri, kimyasal kinetik, kimyasal denge gibi temel konular vardır. İyi bir kimya öğretimi için bahsedilen bu konularının bilinmesi önemli olduğundan matematik ve kimyanın entegrasyonu çok önemlidir. Fen bilimleri öğretmenlerinin 
fen ve matematik programlarının entegrasyonuna yönelik görüşlerinin alındığı bir çalışmada, fen ve matematik öğretim programlarındaki ilişkili konuların uyumlu biçimde sıralanmadığı görüşü ifade edilmiştir (Aytekin ve Aydın, 2017).

Denny (1971), bir lise öğrencisinin kimyasal hesaplamalar yapabilmesi için, aritmetik, parantez kullanımı, negatif ve pozitif sayıların kullanımı, kesirli sayıların kullanımı, ondalıklı sayıların kullanımı, üslü sayıların kullanımı, üstel ve logaritmik denklemlerle işlem yapma, yüzde kullanımı, tek değişkenli denklemlerin çözümü, oran - orantı kullanımı, x-y grafiklerinin çizilmesi ve yorumlanması gibi 10 temel matematiksel beceriye sahip olması gerektiğini ifade etmiştir (akt: Scot, 2012).

Kimya dersleri aynı zamanda birer matematiksel bağıntıya da karşılık gelen ve formül olarak da nitelendirilen pek çok denklem içerir. Örneğin ideal gaz için basınç, hacim ve mutlak sıcaklık arasındaki ilişkiyi veren $\mathrm{PV}=\mathrm{nRT}$ denklemini ele aldığımızda, öğrencilerin denklemi matematik olarak çok değişkenli bir fonksiyon $\mathrm{T}=\mathrm{f}(\mathrm{p} ; \mathrm{V})=\mathrm{pV} / \mathrm{nR}$ şeklinde yorumlamaları gereklidir veya çözeltilerin hazırlanması ve seyreltilmesi ve pH ölçeğinin anlaşılmasında logaritma kullanabilmeleri gereklidir (Cunningham ve Whelan, 2014). Böylece değişkenler arasındaki kimyasal ilişkiyi daha basit bir şekilde ortaya koyabilecekleri açıktır. Üniversite öğrencilerini fizik denklemlerini anlama, yorumlama ve matematiksel ilişkilendirilmesine yönelik çalışmalar mevcuttur (Domert, Airey, Linder, ve Kung, 2007). Kimya derslerinde de pek çok denklem kullanılmasına rağmen öğrencilerinin bu denklemleri anlama, yorumlama ve matematiksel ilişkisinin saptanmasına yönelik çalışmalara rastlanmamıştır. Öte yandan öğrencilerin kimya bilgileri ve kimyada öğrendiği denklemler ile günlük yaşamı ilişkilendirme düzeyinin çok iyi olmadığını gösteren çalışmalara rastlanmıştır (Örneğin, Pekdăg, Azizoğlu, Topal, Ağalar ve Oran, 2013; Balkan ve Aydoğdu, 2011; Üce ve Sarıçayır, 2002; Yıldırım ve Konur, 2014; Ay, 2008; Yiğit, Devecioğlu ve Ayvacı, 2002, Ayas ve Özmen,1999). 
Çalışmanın Amacı: Bu çalışmada fen bilgisi öğretmen adaylarının genel denklem kavramı (çalışma boyunca denklem kavramı, matematiksel denklem olarak anlaşılmalıdır) ve kimya derslerinde öğrendiği veya bazı kimya konularının anlaşılmasında sıklıkla kullanılan denklemlerin, onların zihninde nasıl bir anlam ifade ettiği konusu saptanmak istenmiştir. Bu sebeple kimya derslerinde sık karşılaşılan temel denklemler ele alınarak aşağıdaki sorulara cevaplar aranmıştır.

1. Fen bilgisi öğretmen adaylarının denklem kavramı anlayışları nasıldır?

2. Fen bilgisi öğretmen adaylarının kimya derslerinde kullanılan bazı matematiksel denklemlerle ilgili anlama düzeyleri nasıldır?

\section{Yöntem}

\section{Çalışmanın Deseni:}

Bu çalışmada, öğretmen adaylarının denklem kavramı ve kimya derslerinde kullanılan denklemler konusunda sahip oldukları bilgilerin ortaya çıkartılabilmesi ve bunların matematiksel ilişkisinin belirlenebilmesi için nitel araştırma yöntemlerinin kullanılmasına karar verilmiştir. Strauss ve Corbin (1990) kişilerin deneyim, bilgi ve düşüncelerinin belirlenmesinin amaçlandığ̣ çalışmalarda nitel araştırma yöntemlerinin kullanılmasına vurgu yapmaktadır.

Nitel araştırma yönteminin izlendiği çalışmamızda, verilere ulaşmada döküman analizinden faydalanılmış ve araştırma sorularına yanıt aramak için betimsel analiz kullanılmıştır. Çepni’ye (2014) göre betimsel analiz, kavramsal yapının önceden açık biçimde belirlendiği araştırmalarda kullanılır. Bu amaçla elde edilen veriler, önce sistematik ve açık bir biçimde betimlenir. Daha sonra yapılan bu betimlemeler açıklanır ve yorumlanır, neden sonuç ilişkileri irdelenir ve sonuçlara ulaşılır.

Katılımcılar: Çalışma, 2017-2018 eğitim-öğretim yılı güz döneminde Uludağ Üniversitesi Eğitim Fakültesinde öğrenim gören toplam 50 birinci sınıf Fen Bilgisi öğretmen 
adayı ile gerçekleştirilmiştir. Ülkemizde yaklaşık aynı özellikteki öğrenciler, farklı üniversitelerin fen bilgisi öğretmenliği programını seçmektedir. Bu boyutu ile öğrencilerin alt yapıları birbirine yakın kabul edilmiştir. Öğretmen adayları doğal olarak oluşmuş grupların (sınıf ve organizasyon v.b) ve gönüllülerin araştırma için belirleneceği amaca uygun örnekleme yöntemi ile seçilmiştir (Creswell, 2009). Genel kimya derslerinin birinci sınıf öğrencilerine veriliyor olması sebebiyle çalışmada birinci sınıf fen bilgisi öğretmenliğinde okuyan öğrenciler katılımcı olarak seçilmiştir.

\section{Veri Toplama Aracı:}

Veri toplama aracı olarak araştırmacı tarafından altı adet açık uçlu soru geliştirilmiş ve hazırlanan sorular fen eğitimi alanında çalışmaları olan iki uzmanın görüşüne sunulmuş, gerekli düzeltmeler yapılarak uygulamaya konulmuştur. Onay sonrası açık uçlu soruların yer aldığı formlar öğrencilere dağıtılmıştır. Katılımcılardan her soru veya alt soru için akıllarına birden çok cevap gelirse, en iyi cevabı seçip yazmaları istenmiştir. Böylece betimsel analizde kodların frekanslarının toplamının katılımcı sayısını vermesi amaçlanmıştır. Söz konusu formda yer alan sorular aşağıda belirtilmiştir.

\section{Ölçek Soruları:}

1. Denklem kavramını nasıl tanımlarsınız? Bir denklem gördüğünüzde bu denklem zihninizde nasil bir anlam ifade ediyor?

2. Aşağıda verilen denklemlerin sözel olarak ne ifade ettiğini açıklayınız

$$
\begin{aligned}
& \mathrm{d}=\mathrm{m} / \mathrm{V} \\
& \mathrm{pH}=-\log \left[\mathrm{H}^{+}\right]
\end{aligned}
$$

3. Verilen denklemlerdeki büyüklüklerin ne olduğunu açıklayınız?

$$
\mathrm{E}_{\mathrm{k}}=1 / 2 \mathrm{mv}^{2} \quad \mathrm{M}=\mathrm{n} / \mathrm{V}
$$

4. Üçüncü soruda verilen denklemlerdeki büyüklüklerin birbirini nasıl etkilediğini açıklayınız.

5. Aşağıda verilen denklemlerin matematiksel olarak ne tür denklem ifade ettiğini belirtiniz. 


$$
\mathrm{E}_{\mathrm{k}}=1 / 2 \mathrm{mv^{2 }} \quad \mathrm{M}=\mathrm{n} / \mathrm{V}
$$

6. Aşağıda verilen denklemlerle günlük yaşam arasında nasıl ilişkiler kuralabilir?

$$
\mathrm{P}=\mathrm{F} / \mathrm{A}, \quad \mathrm{P} / \mathrm{T}=\text { sabit }, \quad \mathrm{pH}=-\log \left[\mathrm{H}^{+}\right]
$$

Öğretmen adaylarına bir ders saati süre verilerek, yöneltilen soruları açık bir şekilde yazarak cevaplamaları istenmiştir. Bu aşamadan sonra, tüm bilgilere ilave olarak yeni bilgiler eklenip eklenemeyeceği kaygısıyla 10 öğrenci ile mülakat yapılmıştır. Araştırmanın mülakat aşamasına katılmak isteyen öğrenciler arasından 10 gönüllü fen bilgisi öğretmen adayı belirlenmiş ve önceden belirlenen gün ve saatlerde formda yer alan aynı sorular sözlü olarak sorulmuştur. Adaylar ile yaklaşık birer saat süren görüşmeler yapılmış ve bu süresince adayların verdikleri cevaplar kısa notlar şeklinde kaydedilmiştir. Katılımcıların mülakatlardaki cevaplarının ölçeğe verdikleri cevaplarla uyuştuğu belirlenmiştir. Mülakatlardan özellikle bulguların yorumlanmasında faydalanılmıştır.

\section{Verilerin Analizi}

Çalışmada, açık uçlu sorulara verilen cevapların analizi ile ulaşılan nitel veriler, 'betimsel analiz' yöntemine uygun olarak sunulmuştur. Verilerin analizinde; çerçeve oluşturma, tematik çerçeveye göre verilerin işlenmesi, bulguların tanımlanması ve bulguların yorumlanması basamakları takip edilmiştir (Çepni, 2014). Bu analiz türünde amaç bulguları düzenlenmiş ve yorumlanmış biçimde okuyucuya sunmaktır. Betimsel analizde, görüşülen ya da gözlenen bireylerin görüşlerini çarpıcı biçimde yansıtmak amacıyla doğrudan alıntılara sık sık yer verilir (Yıldırım ve Şimşek, 2013).

Veriler; denklemi tanımlama, sembolleri tanıma, matematiksel ilişkiyi kurma, ve günlük hayatla ilişkilendirmeye ilişkin temalara göre analiz edilmiştir. Temalar, Domert, Airey, Linder, ve Kung (2007) tarafından yapılan çalışmadan alınmıştır. Betimsel analizin amacı, var olan temaların katılım için gerçekleşme düzeyini tespit etmek olduğundan araştırmada da bu temalara göre oluşturulan ölçek sorularına, adayların verdiği cevaplar incelenip analiz 
edildikten sonra kod ve kategoriler oluşturulmuştur. Verilerin kodlanması sürecinde veriler birbirinden bağımsız iki araştırmacı tarafından görüş birliği sağlanıncaya kadar tartışılarak üzerinde çalışılmış ve fen eğitimi alanında çalışması bulunan öğretim üyelerinden görüşler alınmıştır.

Denklem tanımlama temasında, fen bilgisi öğretmen adayları için denklem sözcüğünün ve verilen kimya denklemlerinin ne ifade ettiğinin saptanması amaçlanmıştır. Bu amaçla öğretmen adaylarına bir ve iki numaralı ölçek soruları sorulmuştur.

Sembolleri tanıma temasında, denklemlerde yer alan sembollerin tanınırlığı tespit edilmek istenmiştir. Bir denklemi anlamak onun içindeki sembolleri tanımaya dayanır. Bu amaçla fen bilgisi öğretmen adaylarına üç numaralı ölçek sorusunda kimya derslerinde kullanılan denklemlerden " $E_{\mathrm{k}}=1 / 2 \mathrm{~m} \mathrm{v}, \mathrm{M}=\mathrm{n} / \mathrm{V}$ “ denklemlerindeki sembollerin neler olduğunu açıklamaları istenmiştir.

Matematiksel ilişkiyi kurma temasında; bir denklemdeki büyüklüklerin birbirini nasıl etkilediği ve bir değişken değişirse diğerinin nasıl değiştiğinin belirlenmesi dışında matematiksel ilişki kurulması da amaçlanmıştır. Bu amaçla fen bilgisi öğretmen adaylarına dört ve beş numaralı ölçek soruları sorulmuştur.

Günlük hayatla ilişkilendirme temasında denklemin geçerli olduğu günlük yaşamdaki örnekleri ve durumları tanımlayarak, denklemi günlük yaşam bağlamında ele almak, bu denklemin öğrencinin zihninde ne uyandırdığını anlamak amaçlanmıştır. Burada iki farklı bakış açısı beklenebilir: İlk olarak denklemin anlamına uygun günlük yaşamdan örnekler verilebilir veya ikinci bir ilişki de analojiler bulma biçiminde olabilir (Domert, Airey, Linder, ve Kung, 2007). Bu amaçla altıncı ölçek sorusunda öğretmen adaylarına

$$
\text { “ } \mathrm{P}=\mathrm{F} / \mathrm{A}, \mathrm{pH}=-\log \left[\mathrm{H}^{+}\right], \mathrm{P} / \mathrm{T}=\text { sabit" }
$$

denklemleri verilerek denklemleri günlük yaşamla ilişkilendirmeleri istenmiştir. 
Çalışmada öğretmen adaylarının görüşlerinden doğrudan alıntılara da yer verilmiştir. Öğretmen adaylarının kendi cümleleri doğrudan aktarılacağı için her bir öğretmen adayına Ö $\ddot{\mathrm{O}}_{2}, \ldots$ şeklinde kod isimler verilmiştir.

\section{Geçerlik ve Güvenirlik:}

Araştırmanın iç geçerliliği için uzman incelemesine başvurulmuştur. Temalara ilişkin hazırlanan sorular fen eğitimi alanında uzman öğretim üyelerinin görüşleri alınarak hazırlanmış, temalara ait bulgular alanında uzman öğretim üyelerine sunulmuştur. Temalarla ilgili betimleme kapsamında öğretmen adaylarının görüşmelerde dile getirdiği ifadeler aynen belirtilmiştir.

Araştırmanın güvenirlik tespiti için, öğretmen adaylarının açık uçlu soru ve alt sorulara verdikleri yanıtlar arasından rastgele olarak tüm öğrenci ifadelerinin \%20 si seçilmiştir. Seçilen her ifadenin yanına çalışmada elde edilen olası kategoriler seçenek olarak yerleştirilmiş ve çalışmaya katkı yapmamış bir alan araştırmacısından bu ifadeler için uygun kategorileri seçmesi istenmiştir. Elde edilen sonuca göre "görüş birliğì" ve "görüş ayrılığı" olan kategoriler saptanmıştır. Araştırmanın güvenilirlik hesaplaması için Miles ve Huberman'ın (1994) önerdiği güvenirlik formülü kullanılmıştır.

\section{Güvenirlik = Görüş Birliği / (Görüş Birliği + Görüş Ayrılığı) x100}

Hesaplama sonucunda araştırmanın güvenirliği \%85 olarak hesaplanmıştır ve elde edilen bu değer ile araştırma güvenilir kabul edilmektedir (Miles ve Huberman, 1994).

$\mathrm{Bu}$ çalışmanın sadece Uludağ üniversitesinde okuyan 50 Fen bilgisi öğrencisi ile yürütülmüş olması ve kimya dersi içeriğindeki bazı matematiksel denklemler ile çalışılmış olması sınırlayıcı faktörler olarak ifade edilebilir.

\section{Bulgular}


Araştırmadan elde edilen veriler; denklemi tanımlama, sembolleri tanıma, matematiksel ilişkiyi kurma, ve günlük hayatla ilişkilendirmeye ilişkin temalara göre analiz edilmiştir. $\mathrm{Bu}$ temalara göre oluşturulan ölçek sorularına, adayların verdiği cevaplar incelenip analiz edildikten sonra kod ve kategoriler oluşturulmuştur.

Denklem tanımlama bilgilerini belirleme amacına yönelik olarak sorulan birinci ve ikinci sorular için yapılan analizde, adayların cevapları tek tek incelenmiş ve bilimsel bakış açısı altında anlamı tanımlama, değişkenler arasındaki orantıyı tanımlama ve değişkenlerin sembollerle ifadesi şeklinde kategorileri oluşturulmuş ve aşağıda Tablo-1 ve Tablo-2 de verilen sonuçlar elde edilmiştir.

Tablo 1. Denklem tanımına yönelik ölçekteki birinci sorunun analizine ait bulgular

\begin{tabular}{lllll}
\hline Kodlar & $\mathrm{f}$ & $\%$ & Kategoriler & Tema \\
\hline $\begin{array}{l}\text { İki ya da daha çok değişkenin arasındaki } \\
\text { ilişkinin matematiksel ifadesi }\end{array}$ & 14 & 28 & $\begin{array}{l}\text { Anlamı tanımlama } \\
\text { (Bilimsel tanımı sözel } \\
\text { ifade etme) }\end{array}$ & $\begin{array}{l}\text { Denklemi } \\
\text { Tanımlama }\end{array}$ \\
$\begin{array}{l}\text { En az iki değişkenin bir araya gelmesi ile } \\
\text { oluşan işlemler }\end{array}$ & 8 & 16 & & \\
Bilimsel kavramın formülle ifade şekli & 3 & 6 & & \\
$\begin{array}{l}\text { Kafa karıştırıcı ifadeler } \\
\text { Yoğunluk=kütle/hacim bir denklemdir }\end{array}$ & 6 & 12 & $\begin{array}{l}\text { Değişkenler } \\
\text { arasındaki orantıyı } \\
\text { tanımlama }\end{array}$ & \\
$\begin{array}{l}\text { Denklemdeki değişkenler doğru ya da ters } \\
\text { orantılıdır. }\end{array}$ & 4 & 8 & & \\
$\begin{array}{l}\text { Sayı,,harf ve sembollerle olayların ifadesi } \\
\text { (y= ax+b doğru denklemi) }\end{array}$ & 8 & 16 & Sembollerle ifade & \\
$\begin{array}{l}\text { A+B = C+D gibi Girenler=Çıkanlar } \\
\text { gösterildiği eşitlikler }\end{array}$ & 5 & 10 &
\end{tabular}


Denklemi tanımlama bilgilerini belirleme amacı ile sorulan soruda, denklem tanımı için adaylardan 'iki veya daha çok değişkenler arasındaki ilişkiyi veren matematiksel ifadelerdir' veya 'değişkenler arasındaki ilişkinin sembollerle ifade edilmesi' veya bu ifadelere yakın tanımlar beklenmiştir. Denklem tanımlama bilgilerini belirleme amacı ile sorulan birinci soruya yönelik yapılan analizde, Tablo-1'den de görüldüğü gibi denklem tanımını sözel olarak kendi cümleleri ile açıklayan öğrenci oranı \%54'dür. Bu öğrencilerin \%44' ü tanımı doğruya yakın ifade ederken öğrencilerin \%10’u doğru ifade edememiştir. Öğretmen adaylarının \%46’sı ise, sözel olarak denklemin bilimsel tanımını yapmak yerine değişkenler arasındaki kavramları tanımlamış veya denklemin sembollerle ifade edildiği örnekler üzerinden açıklamalar yapmıştır.

Genel denklem tanımlama teması ve anlamı tanımlama kategorisine ait bazı öğretmen adaylarının görüşleri aşağıdaki gibidir:

Ö1:'Denklem, en az iki değişkenin bir araya gelerek ve işlem özelliğini kullanarak oluşturduğu matematiksel ifadelerdir. Denklem gördüğümde, denklemdeki ifadelerin birbiri ile doğru veya ters orantılı olduğuna bakıyorum.'

Ö4:'Denklem, herhangi bir bilimsel kavramı matematiksel bir yolla ifade etme biçimidir. Ben bir denklem gördüğümde gördüğüm denklemin içinde bulunan terimler sayesinde hangi bilimsel kavramı ifade ettiğini ve hangi yollarla doğru sonuca ulaşabileceğimi anlıyorum.'

Ö20: 'Denklem karışık sayıların, ifadelerin bulunduğu terimdir. Denklem gördüğümde zihnimde karmaşık tuhaf sayılar ve şekiller beliriyor.'

Genel denklem tanımlama teması ve değişkenler arasındaki orantıyı tanımlama ve sembollerle ifade kategorilerine ait bazı öğretmen adaylarının görüşleri aşağıdaki gibidir: Ö22: 'Büyüklüklerin birbiriyle olan bağlantısıdır.'

Ö30: 'A= B/C A, B ve C' ye göre değişir.' 
Tablo 2. Denklem tanımına yönelik ölçekteki ikinci sorunun analizine ait sonuçlar

\begin{tabular}{llllll}
\hline Kodlar & $\mathrm{f}$ & $\%$ & $\begin{array}{l}\text { 2.Sorudaki } \\
\text { Denklemler }\end{array}$ & Kategori & Tema \\
\hline Birim hacimdeki madde miktarı & 16 & 32 & $\mathrm{~d}=\mathrm{m} / \mathrm{V}$ & Verilen & Denklemi \\
Cismin kütlesinin hacme oranı & 23 & 46 & & $\begin{array}{l}\text { denklemlerin } \\
\text { bilimsel tanımını }\end{array}$ & Tanımlama \\
Birim kütledeki hacim & 4 & 8 & & sözel ifade etme \\
Kütle / V & 4 & 8 & & \\
Cevap yok & 3 & 6 & & \\
& & & & denklemlerin \\
Asitlik ölçüsünü gösterir. & 18 & 36 & $\mathrm{pH}=-\log \left[\mathrm{H}^{+}\right]$ & Verilen \\
Asit, baz, nötr & 3 & 6 & & bilimsel tanımını \\
$\mathrm{H}^{+}$derişiminin -log cinsinden asitliği & 13 & 26 & & sözel ifade etme \\
Sudaki pH seviyesini bulmaya yarar. & 2 & 4 & & \\
Asitlik bazlık gösterir & 3 & 6 & & \\
Cevap yok & 11 & 22 & & \\
\hline
\end{tabular}

İkinci soruya yönelik yapılan analizde Tablo-2'den de görüldüğü gibi d=m/V denklemi için 'yoğunluk, birim hacimdeki madde miktarıdır' ifadesini yazarak doğru tanımı yapan öğretmen adayları \%32 iken, adayların \%46'sı yoğunluk kavramının bilimsel tanımını yapamamış ancak formüldeki kavramları okuyarak 'cismin kütlesinin hacme oranı' şeklinde ifade etmiştir. Adayların \%8'i formüldeki V'nin hacim olduğunu doğru olarak ifade edememiş, \%6's1 ise hiç cevap vermemiştir.

İkinci soruda verilen $\mathrm{pH}=-\log \left[\mathrm{H}^{+}\right]$denklemi için; $\mathrm{pH}$ 'asitlik ölçüsünü gösterir' diyerek doğru tanımlama yapan öğretmen adayı sayısı \%36 iken, ' $\mathrm{H}^{+}$derişiminin - log asitliği verir ' ifadesi adayların \%26 tarafından yazılmıştır. Adayların \%12'sinde $\mathrm{pH}=-\log \left[\mathrm{H}^{+}\right]$denklemini gördüğünde, asitlik -bazlık kavramı veya asit-baz-nötr kavramlarının çağrışım yaptığını ifade etmiştir. Öğretmen adaylarının \%4 ‘ü ise pH kavramını sadece suyun pH’ı olarak düşünürken , \%22'si bu denklem hakkında görüş belirtmemiştir.

Bazı öğretmen adaylarının denklemin bilimsel tanımına ait görüşleri aşağıdaki gibidir : 
Ö1: 'Yoğunluk verilen bir cismin kütlesinin kapladığı alana bölünmesi ile hesaplanır. pH bir malzemenin asitlik değerini gösterir $-\log \left[\mathrm{H}^{+}\right]$ise o malzemenin $\mathrm{pH}$ yoğunluğunu gösterir.'

Ö5: 'Birim hacime düşen madde miktarına yoğunluk denir. $\mathrm{pH}=-\log \left[\mathrm{H}^{+}\right]$asitlik değerinin ölçüsüdür.'

Ö25: 'Yoğunluk kütlenin hacme oranından bulunur.'

Sembolleri tanıma temasına yönelik yapılan analizde bu tema için; kavramları doğru tanıma, eksik tanıma, yanlış tanıma ve tanımama şeklinde kategoriler oluşturulmuştur. $\mathrm{Bu}$ amaçla üçüncü ölçek sorusuna verilen öğrenci cevapları tek tek incelenmiş ve aşağıda Tablo-3 de verilen sonuçlar elde edilmiştir.

Üçüncü soruda $E_{k}=1 / 2 \mathrm{~m} \mathrm{v}^{2}, \quad M=n / V$, denklemleri verilerek bu denklemlerdeki büyüklükleri belirtmeleri istenmiştir.

Tablo-3 den de görüldüğü gibi $\mathrm{E}_{\mathrm{k}}=1 / 2 \mathrm{~m} \mathrm{v}^{2}$ denklemindeki semboller $\% 74$ oranında doğru ifade edilirken $M=n / V$ denklemindeki semboller ise \%48 oranında doğru ifade edilmiştir.

Tablo 3. Sembolleri tanımaya yönelik ölçekteki üçüncü sorunun analizine ait sonuçlar

\begin{tabular}{lccclc}
\hline Kodlar & $\mathrm{f}$ & $\%$ & $\begin{array}{l}\text { 3.Sorudaki } \\
\text { Denklemler }\end{array}$ & Kategori & Tema \\
\hline & & & & & \\
E $_{\mathrm{k} \text { - enerji, m -kütle, v-hız }}$ & 37 & 74 & $\mathrm{E}_{\mathrm{k}}=1 / 2 \mathrm{~m} \mathrm{v}^{2}$ & Doğru tanıma & Sembolleri \\
E $_{\mathrm{k}}$-enerji, m -kütle & 3 & 6 & & Eksik tanıma & tanıma \\
m- kütle, v- hız & 2 & 4 & & & düzeyi \\
E $_{\mathrm{k}}$ - Enerjinin formülü & 2 & 4 & & Yanlış tanıma & \\
E $_{\mathrm{k}}$ - Enerji, m kütle, v hacim & 6 & 12 & &
\end{tabular}




$\begin{array}{lllll}\text { M molarite, n mol sayısı, V hacim } & 24 & 48 & \mathrm{M}=\mathrm{n} / \mathrm{V} & \text { Doğru tanıma } \\ \text { n mol sayısı, V hacim } & 6 & 12 & \text { Eksik tanıma } \\ \text { Molarite formülü } & 2 & 4 & \\ \text { M molkütlesi, n mol sayısı, v hacim } & 7 & 14 & \\ \text { Molar } & 4 & 8 & \text { Yanlış tanıma } \\ \text { Cevap yok } & 7 & 14 & \text { Tanımama }\end{array}$

Sembolleri tanıma sorusuna bazı öğretmen adaylarının verdiği cevaplar aşağıdaki gibidir :

Ö7:‘ $E_{k}=1 / 2 m v^{2} E_{k}: K i n e t i k$ enerji, m:kütle, v:hız ; $M=n$ / V M: molarite, v: hacim n:mol.’ Ö19: ' $E_{k}=1 / 2 m v^{2}$ Enerjinin formülü ; $M=n / V$ molarite formülü.'

Matematiksel ilişkiyi kurma teması için, ilişkileri matematik denklemlerle doğru ifade etme, ilişkileri eksik ifade etme, ilişkileri yanlış ifade etme ve ifade edememe şeklinde kategoriler oluşturulmuştur. Matematiksel ilişkiyi kurma bilgilerini belirleme amacına yönelik sorulan dördüncü ve beşinci sorulara yönelik yapılan analizde cevaplar tek tek incelenmiş ve aşağıda Tablo-4 ve Tablo-5 de verilen sonuçlar elde edilmiştir.

Tablo 4. Matematiksel ilişkiyi kurmaya yönelik ölçekteki dördüncü sorunun analizine ait sonuçlar

\begin{tabular}{|c|c|c|c|c|c|}
\hline Kodlar & $\mathrm{f}$ & $\%$ & $\begin{array}{l}\text { 4.Sorudaki } \\
\text { Denklemler }\end{array}$ & Kategori & Tema \\
\hline $\begin{array}{l}\text { H1z ve kütle arttıkça enerji doğru } \\
\text { orantılı olarak artar } \mathrm{m} \text { ile } \mathrm{v}^{2} \text { ters } \\
\text { orantılıdır. } \\
\mathrm{m}, \mathrm{v} \text { artarsa kinetik enerji artar. }\end{array}$ & 28 & 12 & $E_{k}=1 / 2 m v^{2}$ & $\begin{array}{l}\text { Doğru ifade etme } \\
\text { Eksik ifade etme }\end{array}$ & $\begin{array}{l}\text { Matematik- } \\
\text { sel ilişkiyi } \\
\text { kurma }\end{array}$ \\
\hline E, m ile doğru orantılıdır. & 5 & 10 & & & düzeyi \\
\hline Birbirlerine bağlı olarak artarlar. & 4 & 8 & & Yanlış ifade etme & \\
\hline $\mathrm{E}, \mathrm{m}$ ve $\mathrm{v}$ ile ters orant 11 & 5 & 10 & & $\dot{1} \boldsymbol{c} \mathrm{d}$ & \\
\hline Cevap yok & 7 & 14 & & nade edememe & \\
\hline M, n ile doğru, $v$ ile ters orant 11 , & 6 & 12 & $\mathrm{M}=\mathrm{n} / \mathrm{V}$ & Doğru ifade etme & \\
\hline
\end{tabular}


n - v doğru orantılı

$\mathrm{M}, \mathrm{n}$ ile doğru, $\mathrm{v}$ ile ters orantı1ı

$22 \quad 56$

Eksik ifade etme

$\mathrm{M}, \mathrm{n}$ ile ters, $\mathrm{v}$ ile doğru orantılı

$6 \quad 12$

Yanlış ifade etme

$\mathrm{M}, \mathrm{n}$ ve ters orantil1

36

Cevap yok

$7 \quad 14$

İfade edememe

Tablo 4'den de görüldüğü gibi $\mathrm{E}_{\mathrm{k}}=1 / 2 \mathrm{~m} \mathrm{v}^{2}$ denklemi için ilişkilerin doğru ifade edilmesi kategorisinde 'Enerji, kütle ve hızın karesi ile doğru orantılı iken $\mathrm{m}$ ve $\mathrm{v}^{2}$ birbiri ile ters orantılıdır' cevabını \%10 oranında verilirken, ilişkilerin eksik ifade edilmesi şeklinde belirlenen kategoride “m ve $\mathrm{v}$ artarsa kinetik enerji artar 'cevap \%56 oranında verilmiştir. Burada öğrenciler sadece enerji ile kütle-hız ilişkisini belirtmişler, ancak kütle ile $\mathrm{v}^{2}$ arasındaki ilişkiye değinmemişlerdir.

$\mathrm{M}=\mathrm{n} / \mathrm{V}$ denklemi için büyüklüklerin birbiri ile ilişkisini doğru olarak ifade eden öğrenciler $\% 10$ oranında, eksik ifade eden öğrencilerin oranının \%56 olduğu saptanmıştır. Bu durumdaki öğrenciler n-V arasındaki ilişkiyi belirtmemişlerdir. Bu denklem için öğrencilerin \%18'i yanlış ifade ederken, hiç cevap vermeyen öğrenci oranı \%14' dür.

Dördüncü soruya yönelik yönelik olarak bazı öğretmen adaylarının verdiği cevaplar: Ö15: ' $E_{k}=1 / 2 m v^{2}$ de hız ve kütle arttıkça enerji doğru orantılı olarak artar. $M=n / V$ denklemine göre mol artarsa molarite artar hacim artarsa molarite azalır.'

Ö3: 'Verilen büyüklükler türetilmiş büyüklüklerdir.'

Matematiksel ilişkiyi kurma bilgilerini belirleme amacına yönelik sorulan beşinci sorunun analizi Tablo-5 de verilen sonuçlar elde edilmiştir. Beşinci soruda denklemlerin matematiksel olarak ne tür bir denklem ifade ettiği bilgisi incelenmiş ve enerji formülü için ilişkileri doğru ifade edebilme $\% 34$, molarite formülü için $\% 30$, eksik ifade etme 
kategorisindeki cevaplar ise enerji ve molarite formülleri için \%18 civarındadır. Yanlış oranı ise enerji ve molarite formülü için \%40 olarak saptanmıştır.

Tablo 5. Matematiksel ilişkiyi kurmaya yönelik ölçekteki beşinci sorunun analizine ait sonuçlar.

\begin{tabular}{|c|c|c|c|c|c|}
\hline Kodlar & $\mathrm{f}$ & $\%$ & $\begin{array}{l}\text { 5.Sorudaki } \\
\text { Denklemler }\end{array}$ & Kategori & Tema \\
\hline$y=a x^{2}+b x+c$ & 2 & 4 & $\mathrm{E}_{\mathrm{k}}=1 / 2 \mathrm{~m} \mathrm{v}^{2}$ & Doğru ifade etme & Matematik- \\
\hline Parabolik denklem & 2 & 4 & & & sel ilişkiyi \\
\hline 2.derece denklem & 13 & 26 & & & kurma \\
\hline Eğrisel olarak artan bir denklem & 1 & 2 & & Eksik ifade etme & düzeyi \\
\hline Artan ivmeli & 2 & 4 & & & \\
\hline $\mathrm{E}, \mathrm{m}$ ve v ile doğru orant1l1 & 6 & 12 & & Yanlış ifade etme & \\
\hline Doğru orantı denklemi & 20 & 40 & & & \\
\hline Çözemedim & 2 & 4 & & İfade edememe & \\
\hline$y=a x+b$ & 2 & 4 & $\mathrm{M}=\mathrm{n} / \mathrm{V}$ & Doğru ifade etme & \\
\hline 1.derece denklem & 13 & 26 & & Eksik ifade etme & \\
\hline Doğrusal denklem & 9 & 18 & & Yanlış ifade etme & \\
\hline M ve $n$ doğru orantıli & 20 & 40 & & & \\
\hline Bilmiyorum & 6 & 12 & & İfade edememe & \\
\hline
\end{tabular}

Ölçekteki beşinci soruya yönelik bazı öğretmen adaylarının verdiği cevaplar aşağıdaki gibidir:

Ö5: ' $E_{k}=1 / 2 \mathrm{~m} \mathrm{v}^{2} \quad \mathrm{y}=\mathrm{ax}^{2}+\mathrm{bx}+\mathrm{c}$ artan ivmeli denklem, $\mathrm{M}=\mathrm{n} / \mathrm{V} \mathrm{y}=\mathrm{ax}+\mathrm{b}$ doğrusal denklem, Ö41: ' $\mathrm{E}_{\mathrm{k}}=1 / 2 \mathrm{~m} \mathrm{v}{ }^{2}$ ikinci dereceden denklem, $\mathrm{M}=\mathrm{n} / \mathrm{V}$ birinci dereceden denklem.

Günlük hayatla ilişkilendirme bilgilerini belirleme amacına yönelik sorulan ölçekteki altıncı soruya yönelik yapılan analizde öğrenci cevapları tek tek incelenmiş ve aşağıda Tablo6'da verilen sonuçlar elde edilmiştir. Verilen örnekler ile formülde verilen ilişkiler örtüşüyorsa 
uygun örnek, örnekler ile formülde verilen ilişkiler örtüşmüyorsa uygun olmayan örnek şeklinde kategoriler oluşturulmuştur.

Tablo 6. Denklemlerin günlük hayatla ilişkilendirilmesine yönelik ölçekteki altıncı sorunun analizine ait sonuçlar

\begin{tabular}{|c|c|c|c|c|c|}
\hline Kodlar & $\mathrm{f}$ & $\%$ & $\begin{array}{l}\text { 6.Sorudaki } \\
\text { Denklemler }\end{array}$ & Kategori & Tema \\
\hline $\begin{array}{l}\text { Sivri topuklu ayakkabı ile spor } \\
\text { ayakkab1 }\end{array}$ & 18 & 36 & \multirow[t]{11}{*}{$\mathrm{P}=\mathrm{F} / \mathrm{A}$} & \multirow[t]{7}{*}{ Uygun örnek } & \multirow{19}{*}{$\begin{array}{l}\text { Denklemlerin } \\
\text { günlük hayatla } \\
\text { ilişkilendiril- } \\
\text { mesi }\end{array}$} \\
\hline Duvara çivi çakılması & 5 & 10 & & & \\
\hline Sandalyeye uyguladığımız basınç & 3 & 6 & & & \\
\hline $\begin{array}{l}\text { Karda geniş tabanlı ayakkabı ile } \\
\text { yürümek }\end{array}$ & 5 & 10 & & & \\
\hline Sörf tahtas1 & & & & & \\
\hline İ̆̆nenin kumaşa yaptığı basınç & 3 & 6 & & & \\
\hline Bıçakların sivriltilmesi & 2 & 4 & & & \\
\hline Araba lastiklerinin basıncı kışın & 4 & 8 & & \multirow{4}{*}{$\begin{array}{l}\text { Uygun olmayan } \\
\text { örnek }\end{array}$} & \\
\hline düşürülür. & 2 & 4 & & & \\
\hline Hortum ucu büyükse basınç büyür. & & & & & \\
\hline & 2 & 4 & & & \\
\hline Kola & 7 & 14 & \multirow[t]{8}{*}{$\mathrm{pH}=-\log \left[\mathrm{H}^{+}\right]$} & \multirow[t]{8}{*}{ Uygun örnek } & \\
\hline Limon & 5 & 10 & & & \\
\hline Sirke & 5 & 10 & & & \\
\hline Elma & 2 & 4 & & & \\
\hline Kan & 2 & 4 & & & \\
\hline Sabun bazik & 3 & 6 & & & \\
\hline Diş macunu bazik & 4 & 8 & & & \\
\hline Su nötr & 2 & 4 & & & \\
\hline $\begin{array}{l}\text { Yazın araba lastik basıncının } \\
\text { artması }\end{array}$ & 12 & 24 & \multirow[t]{6}{*}{$\mathrm{P} / \mathrm{T}=$ sabit } & \multirow[t]{4}{*}{ Uygun örnek } & \\
\hline Pistonun yukarı hareketi & 6 & 12 & & & \\
\hline Sicakta balon büyür & 3 & 6 & & & \\
\hline Isınan tüpüm patlaması & 2 & 4 & & & \\
\hline Sicakta balon küçülür & 5 & 10 & & \multirow{2}{*}{$\begin{array}{l}\text { Uygun olmayan } \\
\text { örnek }\end{array}$} & \\
\hline Yazın tekerlek basıncı azalır & 12 & 24 & & & \\
\hline
\end{tabular}


Tablo 6 incelendiğinde günlük yaşama ait uygun örneklerin ve en fazla $\mathrm{P}=\mathrm{F} / \mathrm{A}$ denkleminde $\% 80$ oranında verildiği görülmektedir. Bunu sırasıyla $\mathrm{pH}$ ve basınç -sıcaklık ilişkisini veren denklemler izlemektedir. Günlük yaşam ile ilişkili olarak verilen örneklerde en fazla hatanın \%34 ile basınç ile sıcaklık ilişkisinde yapıldığg görülmektedir.

Denklemlerin günlük hayatla ilişkilendirilmesi konusunda bazı öğretmen adaylarının görüşleri aşağıdaki gibidir :

Ö1: 'P (basınç) = ' Topuklu ve spor ayakkabıyı örnek verebiliriz. Yüzey alanı küçüldükçe basınç artar. pH için , diş macunu ve sabunun asitliğinin farklı olduğunu söyleyebiliriz.'

Ö41: ‘ Basıncı dengelemek için kışın karlı havada geniş tabanlı ayakkabı giyeriz.

Satın aldığımız sularda suyun pH' 7 ye yakındır. Sıcaklık arttıkça basınç artar.'

Ö43: ‘ Bıçakların daha keskin olması(daha çok basınç) için sivriltilmesi (alanın küçültülmesi), Suyun pH' 1 arrtıkça tadının sertleşmesi, tüplerin ısındığında patlaması.'

Çalışmada verilen formüllerin günlük hayatla ilişkilendirilmesine yönelik cevaplar incelendiğinde bazı öğrencilerin bu konuda hiçbir cevap yazmadığı görülmüştür.

\section{Tartışma ve Yorum}

Fen bilgisi öğretmen adaylarının zihninde var olan genel denklem kavramı ve kimya derslerinde öğrendiği veya kimya konularının anlaşılmasında kullandığı denklemlerin, onların zihninde nasıl bir anlam ifade ettiği konusunun saptanması amacıyla yapılan çalışmada öğretmen adaylarına yöneltilen altı adet açık uçlu soru; denklemi tanımlama, sembolleri tanıma, matematiksel ilişkiyi kurma, ve günlük hayatla ilişkilendirme temaları altında incelenmiştir.

Denklemi tanımlama bilgilerinin belirlenmesi amaciyla sorulan soruda bazı adaylar denklemin bilimsel tanımını yapmak yerine değişkenler arasındaki kavramları tanımlamış veya denklemin sembollerle ifade edildiği örnekler üzerinden açıklamalar yapmıştır. Bu durum öğrencilerin bilimsel bir tanımı sözel ifade etmede zorlandıkları şeklinde yorumlanabilir. Benzer konuda ortaokul öğrencileri ile yapılan bir çalışmada, öğrencilerin matematik dersinde 
denklem kavramını tanımlaması istenmiş ve bu çalışma sonucuna göre öğrencilerin büyük bölümünün denklem kavramını anlamakta ve tanımlamakta, sorun yaşadıkları görülmüştür. (Dane ve Başkurt, 2012).

Kimyadaki bazı denklemleri tanımlama bilgilerini belirleme amacı ile sorulan soruda, d $=\mathrm{m} / \mathrm{v}$ ile $\mathrm{pH}=-\log \left[\mathrm{H}^{+}\right]$denklemleri verilerek bu denklemlerden yoğunluk ve $\mathrm{pH}$ kavramlarının bilimsel anlamını yazmaları istenmiştir. Adayların büyük çoğunluğu yoğunluk, birim hacimdeki madde miktarıdır tanımını yapamamış, bazıları ise yoğunluk formülündeki değişkenleri yazmış veya formüldeki kavramları dahi doğru olarak ifade edememiştir.

$\mathrm{pH}=-\log \left[\mathrm{H}^{+}\right]$denklemi için, de benzer durum söz konusudur. pH 'asitlik ölçüsünü gösterir' veya ' $\mathrm{H}^{+}$derişiminin - log asitliği verir ' ifadesi denklemin sözel tanımında en fazla yazılan ifadelerdir. Adayların bir kısmı ise denklemini gördüğünde, asitlik -bazlık kavramı veya asitbaz-nötr kavramlarının çağrışım yaptığını ifade etmiştir. Bazı adaylar ise, bu denklem hakkında görüş belirtmemiştir. Bu sonuçlara göre, öğretmen adaylarının büyük bölümünün kullandığ1 formülleri bilimsel anlamda açıklayamamasına rağmen formüldeki değişkenleri tanımaktadır şeklinde yorumlanabilir. Bu durum öğrencilerin denklemleri doğrudan ezberleme eğilimlerinin bir sonucu olarak gözükmektedir. Çünkü eğitim sistemi içinde çeşitli aşamalarda öğrencilerin karşılaştığı değerlendirme ve giriş sınavları sisteminde yöneltilen soru biçimleri, öğrencileri bu şekilde davranmaya yönlendirmiş olabilir. Halbuki öğrencilerden beklenen, denklemin bilimsel anlamını ifade ettikten sonra ilgili bağıntıyı kullanabilmeleridir.

Sembolleri tanıma bilgilerini belirlemek için $\mathrm{E}_{\mathrm{k}}=1 / 2 \mathrm{~m} \mathrm{v}^{2}, \quad \mathrm{M}=\mathrm{n} / \mathrm{V}$, denklemleri verilerek öğretmen adaylarından bu denklemlerdeki büyüklükleri belirtmeleri istenmiştir. $\mathrm{E}_{\mathrm{k}}=$ $1 / 2 \mathrm{~m} \mathrm{v} \mathrm{v}^{2}$ denklemindeki semboller büyük oranında doğru ifade edilmiştir. Kinetik enerji formülündeki yanlışlıklar genellikle hızın(v), hacim olarak algılanmasından kaynaklanmıştır. Kinetik enerji denklemi fizik derslerinde de sıklıkla kullanıldığı için tanınırlığının yüksek olduğu sonucuna ulaşılabilir. $M=n / V$, molarite formülünde ise formüldeki semboller adayların 
büyük çoğunluğu tarafından doğru belirtilmemiş veya hiçbir açıklama yapılmamıştır. Kimyada çözelti derişimleri konusunda işlenmekte olan molarite denklemi kimya dışında diğer derslerde pek yer almadığı ve sıklıkla kullanılmadığı için öğretmen adayları tarafından tanınırlıklarının düşük olduğu söylenebilir. Bu sebeple adayların bu denklemdeki sembolleri açıklamada problem yaşadıkları sonucuna da varılabilir. Benzer şekilde fen ve mühendislik öğrencileri ile yapılan bir çalışmada da öğrencilerin sembolleri tanımada büyük problem yaşadıkları ortaya konmuştur (Gök, 2016).

Matematiksel ilişkiyi kurma bilgilerini belirleme amacı ile sorulan soruda denklemlerdeki büyüklüklerin birbirlerini nasıl etkilediğini belirtmeleri istenmiştir.

$\mathrm{E}_{\mathrm{k}}=1 / 2 \mathrm{~m} \mathrm{v} \mathrm{v}^{2}$ denklemi için ilişkilerin doğru ifade edilmesi kategorisinde 'Enerji, kütle ve hızın karesi ile doğru orantılı iken $\mathrm{m}$ ve $\mathrm{v}^{2}$ birbiri ile ters orantılıdır' cevabı beklenmiş ancak genellikle ilişkiler eksik ifade edilmiştir. Burada adaylar sadece enerji ile kütle-hız ilişkisini belirtmişler, ancak kütle ile $\mathrm{v}^{2}$ arasındaki ilişkiye değinmemişlerdir. $M=n / V$ denklemi için de benzer durumlar söz konusu olup genellikle $\mathrm{n}-\mathrm{V}$ arasındaki ilişkiyi belirtmemişlerdir. $\mathrm{Bu}$ durum, adayların denklemlerdeki büyüklüklerin birbirleri ile olan ilişkisinin farkında olmadığını veya ilişkiyi anlamadan formülü kullandığını göstermektedir. Ayrıca genel bir sorun olarak da denklemlerdeki büyüklüklerin ilişkisini belirtirken sadece eşitliğin iki tarafındaki değişkenlere göre belirlemişler, aynı taraftaki değişkenler arası ilişkileri dikkate almamışlardır. Çalışmadan elde edilen bir sonuç da öğrencilerimizde değişkenler arası matematiksel ilişki, orantı, ters orantı gibi temel matematik bilgisinin de yeterli olmadığı şeklindedir. Bütüner ve Uzun (2011) tarafından yapılan bir çalışmada da fen öğretimi sırasında karşılaşılan matematik temelli sıkıntıların benzer şekilde problemi anlama, grafik çizme, oran orantı ve ters orantı, değişkenler arası ilişkiler ve yüzde hesaplarından kaynaklandığı belirtilmiştir.

Denklemlerin matematiksel olarak ne türden bir denklem ifade ettiği sorusu için özellikle birinci ve ikinci dereceden denklemlere karşılık gelen iki örnek seçilmiştir. Elde edilen 
sonuçlar öğrencilerin büyük bölümünün $M=n / V$ denklemini $y=a x+b$ gibi doğru denklemi ile, $\mathrm{E}_{\mathrm{k}}=1 / 2 \mathrm{~m} \mathrm{v}^{2}$ denklemini ise $\mathrm{y}=\mathrm{ax}^{2}+\mathrm{bx}+\mathrm{c}$ gibi parabol denklemi ile ilişkilendiremediğini göstermiştir. Burada adayların matematiksel bakış açısıyla yorum getirmeleri son derece yetersizdir. Bu bakış açısına sahip olmaları, fen kavramları arasındaki ilişkileri açıklamaları ve yorum katmaları açısından çok önemli görülmektedir. Benzer sonuçlara Ergül (2017) nin çalışmasında da ulaşıldığı görülmüştür.

Son olarak günlük hayatla ilişkilendirme bilgilerini belirleme amacı ile sorulan soruda, $\mathrm{P}=\mathrm{F} / \mathrm{A}, \mathrm{P} / \mathrm{T}=$ sabit ve, $\mathrm{pH}=-\log \left[\mathrm{H}^{+}\right]$, denklemleri verilerek denklemler ile günlük yaşam arasında ilişkiler kurmaları istenmiştir. $\mathrm{P}=\mathrm{F} / \mathrm{A}$ denklemi doğrudan kimya ile ilgili olmamakla birlikte, kimyada gazlar ünitesinde sıvı basıncından gaz basıncının hesaplanması konusunda işlenmektedir. Öğretmen adayları, verilen denklemlere uygun günlük yaşamdan örnekler vermeye çalışmış ancak denklemleri basitleştirerek açıklayınız şeklinde bir yönlendirme yapılmadığı için hiçbir aday, ilişkiyi kurmada Domert, Airey, Linder ve Kung (2007)’ un söz ettiği ikinci bir yaklaşım olan analojiler kullanarak denklem ve günlük yaşam ilişkisi bulmaya çalışmamıştır.

Günlük yaşama ait uygun örneklerin ve en fazla $P($ basınç $)=F / A$ denkleminde verildiği görülmektedir. Bunu sırasıyla pH ve basınç -sıcaklık ilişkisini veren denklemler izlemektedir. Günlük yaşam ile ilişkili olarak verilen örneklerde en fazla hatanın da basınç ile sıcaklık ilişkisinde yapıldığı görülmektedir. Basınç-hacim arasındaki ters orantı ilişkisinin öğrencilerin zihninde basınç- sıcaklık ilişkisine benzetildiği, yani matematiksel ilişkiyi göz önüne almadan yorumladıkları görülmüştür. Bu bulgu, sınıf öğretmeni adaylarının gazlarda sıcaklık-hacimbasınç ilişkisini anlama seviyelerini ve güncel hayattaki örnekleri bu konuyla ne derece ilişkilendirebildiklerini tespit etmek amacı ile yapılmış bir çalışmanın bulgularıyla örtüşmektedir (Konur ve Ayas, 2010). Ayrıca, Nakiboğlu ve Arık (2006) tarafından yapılan başka bir çalışmada da gazlarda sıcaklık-hacim ilişkisini anlamada öğrencilerin problem 
yaşadıkları ortaya konulmuştur. Yapılan pek çok çalışma, bulguları destekler biçimde, öğrencilerin kimya bilgileri ve kimyada öğrendiği denklemler ile günlük yaşamı ilişkilendirme düzeyinin çok iyi olmadığını göstermektedir (Örneğin, Pekdağ, Azizoğlu, Topal, Ağalar ve Oran, 2013; Ay, 2008; Balkan ve Aydoğdu, 2011; Üce ve Sarıçayır, 2002; Yıldırım ve Konur, 2014; Yiğit, Devecioğlu ve Ayvac1, 2002).

\section{Öneriler}

Fen ve matematik eğitiminin bütünleştirilmesi, matematik ve fen ile ilgili öğrenci başarı ve tutumlarının iyileştirilmesine yönelik bir yol olarak önerilebilir. Örneğin matematik derslerinde fonksiyonlar konusu işlenirken bu fonksiyonlara uygun kimya denklemlerine ait örnekler verilmesi öğrencilerin bu denklemlere bakış açılarını genişleterek konuları daha iyi kavramalarına yol açacağı söylenebilir. Öğrencilerimiz denklemleri problemlerin bağlamına dikkat etmeksizin çözümünde işe yarar birer formül olarak değerlendirmektedir. Böylece denklemlerin anlam ve içeriğini kavramaya önem vermeyip, doğrudan ezberleme yoluna gitmektedir. Öğrencilerimize denklemlerin aslında bir bilimsel ifadenin kısaltılmış veya sembollere indirgenmiş hali olduğu öğretilmelidir. Böylece denklem kavramı ve denklemin anlamı anlaşılır hale getirilmelidir. Yani denklemin sadece problemlerin çözümünde gereken formüller olarak algılanması önlenmelidir.

Eğitimcilerin, bu bakış açısını yok edecek doğrultuda bir içerikle öncelikle denklemlerin bilimsel anlamlarını, denklemi oluşturan büyüklükler ve büyüklükler arası ilişkileri, matematik bilgisiyle de bütünleştirerek öğretmeye yönelik öğretim ortamı sağlamaları uygun olacaktır.

\section{Makalenin Bilimdeki Konumu (Yeri)}

Matematik ve Fen Bilimleri Bölümü/ Fen Bilgisi Eğitimi Anabilim Dalı, Kimya Eğitimi.

\section{Makalenin Bilimdeki Özgünlüğü}

Fen bilgisi öğretmen adaylarının kimya derslerinde sıkça kullanılan denklemler ile, matematiksel ilişkiyi kurabilmeleri, fen kavramları arasındaki ilişkileri açıklamaları ve yorum 
katmaları açısından çok önemli görülmektedir. Bu makalede bu sorun ortaya konmuş ve çözüm önerileri sunulmuştur. Bu açıdan bakıldığında, öğretmen ve öğretmen adaylarının yanı sıra eğitim programcılarının bu konuya dikkatini çekmek bakımından alana katkı sağlayacağı söylenebilir.

\section{Kaynakça}

Ay, S. (2008). Lise seviyesinde öğrencilerin günlük yaşam olaylarını açıklama düzeyi ve buna kimya bilgilerinin etkisi. Yayınlanmamış Yüksek Lisans Tezi, Marmara Üniversitesi Fen Bilimleri Enstitüsü, İstanbul.

Ayas, A. ve Özmen, H. (1999). Asit-baz kavramlarını güncel olaylarla bütünleştirilme seviyesi: Bir örnek olay çalışması. III. Ulusal Fen Bilimleri Eğitimi Sempozyumu, Karadeniz Teknik Üniversitesi, Trabzon.

Aytekin, C. ve Aydın, F. (2017). Opinions of Science Teachers About Integration of Science and Mathematics Curriculum. Uludă̆ Üniversitesi Eğitim Fakültesi Dergisi, 30 (2), 443-464.

Balkan-Kıyıcı, F. ve Aydoğdu, M. (2011). Fen bilgisi öğretmen adaylarının günlük yaşamları ile bilimsel bilgilerini ilişkilendirebilme düzeylerinin belirlenmesi. Necatibey Ĕ̆itim Fakültesi Dergisi, 5(1), 43-61.

Bütüner, S. Ö. ve Uzun, S. (2011). Fen öğretiminde karşılaşılan matematik temelli sıkıntılar: Fen ve Teknoloji Öğretmenlerinin Tecrübelerinden Yansımalar,Kuramsal Ĕ̈itimbilim, 4 (2), 262-272.

Cunningham, A. ve Whelan, R. (2014). Maths for Chemists, University of Birmingham, Mathematics support centre .

Creswell, J. W. (2009). Research design: Qualitative, quantitative, and mixed methods approaches. Sage publications. 
Çepni, S. (2014). Araştırma ve Proje Çalışmalarına Giriş, Trabzon: Celepler Matbaacılık.

Dane. A. ve Başkurt H. (2012). Perceptıon Levels Of The Concepts of Identıfication and Equation of the Elementary Grade Eight Students and Their Learning Difficulties. The Journal of Academic Social Science Studies, 5 (8), 397-413.

Deny. (1971) ( akt: Fraser, J.S. (2012). Is the mathematics to blame? An investigation in to high school students' diffuculty in performing calculations in chemistry education. Research and Practice, Chem. Educ. Res. Pract.,13, 330-336.

Deringöl, Y. ve Gülten D.Ç. (2016). Öğretmen Adaylarının Fen Eğitiminde Matematiğin Kullanılması ile İlgili Görüşleri: Bir Metafor Analizi Çalışması. Eğitim ve Öğretim Araştırmaları Dergisi, 5 (1).

Domert, D., Airey, J., Linder, C. ve Kung, R. (2007). An exploration of university physics students' epistemological mindsets towards the understanding of physics equations. NorDiNa, Nordic Studies in Science Education (3), 15- 28.

Ergül, N. R.(2018). Pre-service Science Teachers' Construction and Interpretation of Graphs. Universal Journal of Educational Research 6(1), 139-144.

Gök, T.( 2016). The Importance Of Symbols and Unıts In Natural Science. The Eurasia Proceedings of Educational \& Social Sciences (EPESS), Volume 4, 165-167

Leopold, D. G. ve Edgar, B. ( 2008). Degree of Mathematics fluency and Success in SecondSemester Introductory Chemistry. Journal of Chemical Education, 85(5 ).

Miles, M. B. \& Huberman, A.M. (1994). Qualitative data analysis : an expanded sourcebook. (2nd Edition). Calif. : SAGE Publications.

Milne, G. W. A. (1997). Mathematics as a basis for chemistry. J. Chem. Inf. Comput. Sci., 37, 639-644. 
Nakiboğlu, C. ve Özkılıç Arık, R. (2006). 4. Sınıf öğrencilerinin gazlar ile ilgili kavram yanılgılarının v-diyagramı kullanılarak belirlenmesi. Yeditepe Üniversitesi Ĕ̈itim Fakültesi Dergisi, 1(2).

Ogilvie, J. F. ve Monagan, M. B. (2007). Teaching mathematics to chemistry students with symbolic computation. Journal of Chemical Education, 84(5).

Özdemir, N. (2006). İlköğretim 2. kademedeki fen bilgisi öğretiminde yaşanan sorunlar ve çözüm önerileri. (Yayımlanmamış yüksek lisans tezi). Pamukkale Üniversitesi Fen Bilimleri Enstitüsü, Denizli.

Pekdağ, B., Azizoğlu, N., Topal, F., Ağalar, A. ve Oran, E.(2013). Kimya Bilgilerini Günlük Yaşamla İlişkilendirme Düzeyine Akademik Başarının Etkisi. Kastamonu Eğitim Dergisi. Cilt:21 No:4 (Özel Say1) 1275-1286.

Redish, E. F. ve Kuo, E. (2015). Language of physics, language of math: disciplinary culture and dynamic epistemology. Sci \& Educ, 24, 561-590.

Scott, F. J. (2012). Is mathematics to blame? An investigation into high school students' difficulty in performing calculations in chemistry. Chemistry Education Research and Practice, Chem. Educ. Res. Pract., 13, 330-336.

Sherin, B.L.(2001). How students understand physics equation. Cognitıon and instruction, 19(4), 479-541.

Strauss, A. ve Corbin, J. (1990). Basics of qualitative research.Vol15 Newbury Park, CA: Sage .

Sujak, K. B. ve Daniel, G.S. (2017). Understanding of Macroscopic, Microscopic and Symbolic Representations Among Form Four Students in Solving Stoichiometric Problems, Malaysian Online Journal of Educational Sciences, Volume 5 - Issue 3. 
Temel, H., Dündar, S. ve Şenol, A. (2015). Öğretmenlerin Fen ve Teknoloji Dersinde Matematikten Kaynaklanan Güçlükleri Giderme Yolları ve Fen Matematik Entegrasyonunun Önemi, GEFAD / GUJGEF, Volume 35 Issue 1, 153-176.

Tuminaro, J. (2002). How Students Use Mathematics in Physics: A Brief Survey of the Literature, University of Maryland College Park.

Tutak, T., Gül, Z. ve Emür, N. (2010). Matematik Eğitiminde İlköğretim Düzeyinde Kavramla İlgili Yapılan Çalışmaların Bir Değerlendirmesi, 9. Ulusal Sınıf Öğretmenliği Ĕğitimi Sempozyumu, Elazı̆̆.

Üce, M. ve Sarıçayır, H. (2002). Üniversite 1. sınıf genel kimya dersinde asit-baz konusunun öğretiminde kavramsal değişim metinleri ve kavram haritalarının kullanılması. M. $\ddot{U}$. Atatürk Eğitim Fakültesi Ĕ̆itim Bilimleri Dergisi, 16, 163-170.

Yaman, Y. ve Gülten D. Ç. (2015). Fen ve Matematik Öğretmen Adaylarının Matematik Öğretiminde Kullanılan Dile İlişkin Görüşlerinin Araştırılması, Eğitim ve Öğretim Araştırmaları Dergisi, Journal of Research in Education and Teaching ,4 (4), Makale No: 25.

Yenilmez, K. (2007). İlköğretim Matematik Öğretiminde Karşılaş1lan Zorluklar ve Nedenleri, XVI. Ulusal Eğitim Bilimleri Kongresi, Gaziosmanpaşa Üniversitesi Eğitim Fakültesi, Tokat.

Yıldırım, A., ve Şimşek, H. (2013). Sosyal bilimlerde nitel araştırma yöntemleri. (9.baskı) Ankara: Seçkin Yayıncılık.

Yıldırım, C. (2005). Bilimin Öncüleri, Tübitak Popüler Bilim Kitapları, 22. Basım, Ankara: Yenigün Matbaası.

Yıldırım, N. ve Birinci Konur, K. (2014). Fen bilgisi öğretmen adaylarının kimya kavramlarını günlük hayatla ilişkilendirebilmelerine yönelik gelişimsel bir araştırma. JASS, 30, 305323. 
Yiğit, N., Devecioğlu, Y. ve Ayvacı, H.Ş. (2002). İlköğretim fen bilgisi öğrencilerinin fen kavramlarını günlük yasamdaki olgu ve olaylarla ilişkilendirme düzeyleri. V. Ulusal Fen Bilimleri ve Matematik Eğitimi Kongresi ODTÜ Eğitim Fakültesi, Ankara.

\section{Pre-service science teachers' understanding and level of comprehension of chemistry equations}

\section{Problem statement:}

Knowing mathematics and using its knowledge are the most important conditions for success in science courses. Knowledge and skills of students using mathematics in basic science courses are the main factors affecting their success in the course. Many researches on the subject have identified the necessary mathematical skill as a priority feature besides the other factors for success in the relevant discipline of science (Scott, 2012).

Mathematics is primarily and profoundly influential in both teaching and practicing physiology. Moreover, other sciences such as chemistry, biology, geology and meteorology often use mathematics (Redish and Kuo, 2015).Despite the fact that there are many studies on the use and importance of mathematics in physics, the studies that investigate the relationship between mathematics and chemistry are less common.

Many studies have shown that students have problems using mathematical knowledge at all levels (Milne, 1997; Sherin, 2001, Akerer and Uzun, 2011: Yenilmez, 2007; Ogilvie and Monagan, 2007; Leopold and Edgar, 2008; Tutak, Gül and Emür, 2010; Scott, 2012; Redish, Kuo, and Daniel, 2017). One of the most important reasons for this is that mathematics and science courses are not well integrated and this problem creates a gap between mathematics and science lessons.

\section{Purpose of the study:}


In this study, basic equations which are frequently encountered in chemistry were investigated and answers to these equations were searched in order to gain a profound point of view to determine the concept of general equations in science students' minds and the equations they used.

\section{Method:}

In this study, the descriptive analysis method which is one of the qualitative research methods was used to search for answers to research questions.

The study was conducted with a total of 50 first-year science teachers who were educated at the Uludağ University Faculty of Education during the fall semester of the 20172018 academic year. Six open-ended questions were developed by the researcher as data collection tools and directed at the students. Within one class hours, they were expected to write the questions clearly and step by step.

\section{Findings and Conclusion:}

The answers given by the students to the questions asked for the purpose of determining the equation definition information, the symbols recognition information, the mathematical relation formation information and the association with daily life were examined one by one and the obtained results were given in the tables.

According to these results, most of the students know the concepts in the formula although they can not explain the formulas using scientific terms. This seems to be a result of students' tendency to memorize equations directly. The expected result here is that they can use the related connection after they have expressed the scientific meaning. When the answers to the questions asked to identify the symbols are examined, because the equations used in the physics lessons as well as the chemistry lessons are often utilized, it results with a high recognition of the symbols in these equations. When examining the answers to the question 
asked to determine the mathematical relation-building information, it is shown that the students are either not aware of the relationship between the quantities in the equations or use the formula without the sense of relation. It is also clear that the results are far from the mathematical point of view of the students. Similar results have been found in the study of Ergül (2017). Finally, when we relate the equations to daily life, the students tried to give examples from the daily life appropriate to the equations, but they tended not to find an analogy about the equations in this relationship.

The integration of science and mathematics education can be suggested as a way to improve student achievement and attitudes in mathematics and science. For example, while describing functions in mathematics lessons, giving examples of physics and chemistry equations suitable for these functions will lead to better understanding of the subjects by expanding the points of view of these equations. 